\title{
Pengaruh Pergeseran Waktu Perjalanan Terhadap Tingkat Pelayanan Jalan di Koridor Jalan By Pass Ngurah Rai Jimbaran, Bali
}

\author{
Dian Khairul Lubis dan Siti Nurlaela \\ Perencanaan Wilayah dan Kota, Fakultas Arsitektur, Desain, dan Perencanaan \\ Institut Teknologi Sepuluh Nopember (ITS) \\ E-mail: siti.nurlaela@postgrad.curtin.edu.au
}

\begin{abstract}
Abstrak-Koridor Jalan By Pass Ngurah Rai adalah koridor utama penghubung kawasan Bali Selatan dengan wilayah Denpasar dan sekitarnya. Kemacetan yang terjadi di koridor ini sudah sangat krusial dan dapat mengganggu aktivitas perekonomian Bali Selatan. Dengan mayoritas penggunaan lahan adalah perdagangan dan jasa, pergerakan di koridor jalan By Pass Ngurah Rai Jimbaran memicu bangkitan yang cukup besar dari pelaku pergerakan rutin ke kawasan tersebut Penelitian ini bertujuan untuk mengetahui seberapa besar pengaruh pergeseran waktu perjalanan terhadap tingkat pelayanan jalan di koridor jalan By Pass Ngurah Rai Jimbaran. Berdasarkan hasil analisis didapatkan bahwa pelaku perjalanan didominasi oleh pelaku perjalanan dengan tujuan ke perdagangan dan jasa dengan maksud perjalanan adalah untuk bekerja. Moda kendaraan yang banyak digunakan adalah sepeda motor. Alternatif skenario TDM yang dapat diterapkan untuk koridor Jalan By Pass Ngurah Rai bervariasi untuk setiap penggunaan lahannya. Berdasarkan hasil analisis regresi, diketahui bahwa hanya penggunaan lahan fasilitas pendidikan dan perdagangan dan jasa saja yang memiliki pengaruh yang signifikan terhadap tingkat pelayanan jalan. Setelah itu dilakukan pengestimasian besar volume setelah penerapan skenario TDM yaitu flexible time, staggered shift, pembatasan waktu berkendara, compressed week, dan pembatasan aktivitas bongkar muat, dan penyimulasian perubahan besar volume dan perubahan derajat kejenuhan akibat penerapan skenario TDM tersebut. Dari hasil simulasi tersebut, penerapan skenario TDM di kedua penggunaan lahan tersebut memberikan dampak yang bervariasi terhadap tingkat penggunaan lahan.
\end{abstract}

Kata Kunci-Kemacetan, Transport Demand Management, Pergeseran Waktu, Tingkat Pelayanan Jalan.

\section{PENDAHULUAN}

K EMACETAN terjadi ketika arus lalu lintas yang lewat pada ruas jalan yang ditinjau melebihi kapasitas rencana jalan tersebut yang mengakibatkan kecepatan bebas ruas jalan tersebut mendekati atau melebihi $0 \mathrm{~km} / \mathrm{jam}$ sehingga menyebabkan terjadinya antrian[1]. Kemacetan lalu lintas terjadi karena beberapa faktor, seperti banyak pengguna jalan yang tidak tertib, pemakai jalan melawan arus, kurangnya petugas lalu lintas yang mengawasi, adanya mobil yang parkir di badan jalan dan permukaan jalan yang tidak rata[2]. Kemacetan membawa berbagai dampak negatif antara lain: kerugian waktu karena kecepatan yang rendah, pemborosan energi, keausan kendaraan lebih tinggi, mengingkatkan polusi udara, meningkatkan stress pengguna jalan, dan mengganggu kendaraan darurat.

Jalan By Pass Ngurah Rai Jimbaran merupakan satusatunya jalan yang menghubungkan wilayah Bukit di Bali bagian Selatan dengan wilayah Denpasar dan sekitarnya mengalami tingkat kemacetan yang sudah sangat krusial.
Menurut RTRW Provinsi Bali tahun 2009-2029, koridor Jalan By Pass Ngurah Rai memiliki fungsi jalan Kolektor Primer yaitu jalan umum yang berfungsi melayani angkutan pengumpul atau pembagi dengan ciri perjalanan jarak sedang, kecepatan rata-rata sedang, dan jumlah jalan masuk dibatasi.

Salah satu solusi mengatasi kemacetan adalah dengan menerapkan Transport Demand Management (TDM) atau Manajemen Kebutuhan Transportasi (MKT)[3]. Transport Demand Management merupakan suatu strategi untuk memaksimalkan efisiensi sistem transportasi perkotaan melalui pembatasan penggunaan kendaraan pribadi dan mempromosikan moda transportasi yang lebih efektif, sehat dan ramah lingkungan[3]. Kebijakan yang dapat dilakukan dalam pelaksanaan konsep TDM harus dapat berdampak pada perubahan perilaku transportasi. Dampak pertama adalah dampak pergeseran waktu yaitu proses pergerakan terjadi pada lokasi yang sama, tetapi pada waktu yang berbeda. Dampak kedua adalah dampak pergeseran rute atau lokasi yaitu proses pergerakan terjadi pada waktu yang sama, akan tetapi pada rute atau lokasi yang berbeda. Ketiga, dampak pergeseran moda yaitu proses pergerakan terjadi pada lokasi yang sama dan waktu yang sama, akan tetapi dengan moda transportasi yang berbeda. Keempat, dampak pergeseran lokasi tujuan yaitu proses pergerakan terjadi pada lokasi yang sama, waktu yang sama, dan moda transportasi yang sama, tetapi dengan lokasi tujuan yang berbeda[4].

Konsep Transport Demand Management dapat dikatakan sebagai pendekatan yang mengkombinasikan elemen voluntary (sukarela) dan program regulasi [5]. Penerapan konsep TDM ini bisa diterapkan secara voluntary (sukarela) dari pelaku pergerakan itu sendiri maupun diatur dengan menggunakan regulasi oleh pemangku kepentingan. Pemilihan pergeseran waktu perjalanan sebagai solusi mengatasi permasalahan kemacetan adalah karena pergeseran waktu perjalanan lebih memungkinkan untuk dilakukan karena kurang terkait langsung dengan pemanfaatan sistem transportasi, memberikan jaminan bahwa masalah transportasi akan terpecahkan saat strategi-strategi dalam pergeseran waktu diterapkan.

\section{TEORI PENUNJANG}

\section{A. Metode Pengumpulan Data}

Metode pengumpulan data yang dilakukan pada penelitian ini meliputi pengumpulan data secara primer maupun sekunder. Pengumpulan data secara primer dilakukan dengan pengamatan langsung, wawancara dan pembangian kuesioner. Pengamatan langsung yang dilakukan adalah mengamati kondisi lapangan seperti kondisi fisik ruas jalan, 
penggunaan lahan eksisting, menghitung bangkitan dan tarikan dari sample kapling penggunaan lahan dengan menghitung kendaraan yang keluar dan masuk, menghitung volume kendaraan melalui traffic counting di ruas jalan koridor. Sedangkan, untuk pengumpulan data secara sekunder dilakukan dengan survei instansi dimana instansi yang dituju adalah Dinas Perhubungan Kabupaten Badung dan Dinas Pekerjaan Umum dan Penataan Ruang Kabupaten Badung.

\section{B. Variabel Penelitian}

Dalam melakukan penelitian pengaruh pergeseran waktu perjalanan terhadap tingkat pelayanan jalan di koridor jalan By Pass Ngurah Rai digunakan beberapa variabel penelitian sebagai tolak ukur. Penentuan dari variabel penelitian ini didasarkan pada hasil sintesa dari berbagai pustaka ilmiah. Berikut merupakan tabel variabel dari penelitian ini.

Tabel 1.

Indikator, Variabel dan Definisi Operasional

\begin{tabular}{|c|c|c|}
\hline Indikator & $\begin{array}{c}\text { Variabel dalam } \\
\text { Teori } \\
\end{array}$ & Definisi Operasional \\
\hline $\begin{array}{l}\text { Karakteristik } \\
\text { pengguna lalu }\end{array}$ & Lokasi Asal & $\begin{array}{ll}\text { Titik awal perjalanan } \\
\text { dilakukan }\end{array}$ \\
\hline lintas & Lokasi Tujuan & Titik akhir perjalanan selesai \\
\hline & $\begin{array}{l}\text { Jarak dari tempat } \\
\text { asal ke tempat tujuan }\end{array}$ & $\begin{array}{l}\text { Satuan panjang yang harus } \\
\text { ditempuh pelaku pergerakan } \\
\text { dari titik awal bergerak ke } \\
\text { titik tujuan }\end{array}$ \\
\hline
\end{tabular}

$\begin{array}{lll}\text { lokasi tujuan } & \text { untuk melakukan perjalanan }\end{array}$ dari titik awal ke titik tujuan

Maksud Perjalanan Alasan melakukan perjalanan dari lokasi asal ke lokasi tujuan

Lama aktivitas

Lama waktu mulai aktivitas hingga aktivitas berakhir

Moda Kendaraan Moda yang digunakan pelaku pergerakan.

Karakteristik

Jumlah Kendaraan arus lalu lintas

Jumlah kendaraan yang melintas di koridor studi pada saat pengamatan dilakukan

Jenis Kendaraan

Spesifikasi kendaraan yang melintas di koridor studi pada saat pengamatan dilakukan (kendaraan berat, kendaraan ringan, sepeda motor, dan non-motorize)

Kapasitas Jalan

Ukuran kemampuan jalan dalam menampung volume kendaraan

Karakteristik Pergerakan

Pergerakan internal- Lokasi asal dan lokasi tujuan internal perjalanan berada di dalam kawasan studi

Pergerakan internal- Lokasi asal perjalanan eksternal

Pergerakan eksternal-internal

Pergerakan eksternal-eksternal berada di dalam kawasan studi, sementara lokasi tujuan pergerakannya berada di luar kawasan studi

Lokasi asal perjalanan berada di luar kawasan studi sementara lokasi tujuan perjalanannya berada di dalam kawasan studi

Lokasi asal dan lokasi tujuan perjalanan berada di luar kawasan studi

Tingkat Bangkitan

\begin{tabular}{|c|c|c|}
\hline \multirow[t]{3}{*}{$\begin{array}{l}\text { Perjam Perguna } \\
\text { Lahan }\end{array}$} & Jumlah bangkitan & $\begin{array}{lcc}\text { Jumlah } & \text { bangkitan } & \text { yang } \\
\text { terjadi } & \text { pada } & \text { setiap }\end{array}$ \\
\hline & & $\begin{array}{l}\text { penggunaan lahan pa } \\
\text { setiap jamnya }\end{array}$ \\
\hline & $\begin{array}{l}\text { Waktu keluar-masuk } \\
\text { kendaraan pada } \\
\text { setiap jenis } \\
\text { penggunaan lahan }\end{array}$ & \begin{tabular}{lcr} 
Waktu & \multicolumn{2}{c}{ keluar-masuk } \\
kendaraan & pada & setiap \\
penggunaan & lahan & yang \\
disurvey & &
\end{tabular} \\
\hline \multirow[t]{6}{*}{$\begin{array}{l}\text { Alternatif } \\
\text { Strategi TDM } \\
\text { yang berkaitan } \\
\text { dengan waktu }\end{array}$} & $\begin{array}{l}\text { Jam masuk yang } \\
\text { fleksibel }\end{array}$ & $\begin{array}{l}\text { Memberikan pilihan untu } \\
\text { masuk kantor atau sekola } \\
\text { dengan waktu yang tida } \\
\text { menetap }\end{array}$ \\
\hline & $\begin{array}{ll}\text { Pemadatan } & \text { Waktu } \\
\text { Efektif } & \text { dalam } \\
\text { Seminggu } & \end{array}$ & $\begin{array}{l}\text { Pemadatan waktu kerja } \\
\text { maupun sekolah dari yang } \\
\text { semula } 6 \text { hari menjadi } 5 \text { hari } \\
\text { atau kurang }\end{array}$ \\
\hline & $\begin{array}{l}\text { Pembedaan waktu } \\
\text { masuk dan keluar } \\
\text { dari kantor dan } \\
\text { sekolah }\end{array}$ & $\begin{array}{l}\text { Waktu masuk dan keluar } \\
\text { dari kantor dan sekolah tidak } \\
\text { berada pada waktu yang } \\
\text { sama untuk menghindari } \\
\text { pergerakan secara bersama- } \\
\text { sama dalam satu waktu }\end{array}$ \\
\hline & $\begin{array}{l}\text { Pembatasan waktu } \\
\text { pergerakan }\end{array}$ & $\begin{array}{l}\text { Pelaku perjalanan dibatas } \\
\text { untuk melakukan aktivitas } \\
\text { berkendara di jam-jan } \\
\text { tertentu }\end{array}$ \\
\hline & $\begin{array}{l}\text { Pemberlakuan } \\
\text { pembatasan waktu } \\
\text { aktivitas bongkar- } \\
\text { muat }\end{array}$ & $\begin{array}{l}\text { Aktivitas bongkar-mu } \\
\text { barang hanya bisa dilakuka } \\
\text { pada jam-jam tertentu }\end{array}$ \\
\hline & $\begin{array}{l}\text { Mengganti aktifitas } \\
\text { berkendara dengan } \\
\text { teknologi dan } \\
\text { telekomunikasi }\end{array}$ & $\begin{array}{l}\text { Pergerakan yang } \\
\text { dimaksudkan untuk } \\
\text { menjalankan aktifitas, } \\
\text { digantikan dengan teknologi } \\
\text { dan telekomunikasi }\end{array}$ \\
\hline
\end{tabular}

\section{Metode Analisis}

Dalam melakukan analisis pengaruh pergeseran waktu perjalanan terhadap tingkat pelayanan jalan By Pass Ngurah Rai dilakukan dengan enam tahapan analisis yakni:

1) Mengidentifikasi Karakteristik Pelaku Perjalanan

Karakteristik pelaku perjalanan pada penelitian kali ini mencakup lokasi asal-tujuan pelaku pergerakan, waktu tempuh keberangkatan dan waktu tempuh kepulangan, lama waktu aktifitas berlangsung, maksud perjalanan, serta moda kendaraan yang digunakan pelaku pergerakan. Alat analisis yang digunakan adalah analisis statistik deskriptif.

2) Mengidentifikasi Karakteristik Arus Lalu Lintas

Karakteristik arus lalu lintas ini mencakup identifikasi pelayanan jalan di Koridor Studi di setiap jam selama penelitian. Alat analisis yang digunakan adalah analisis tingkat pelayanan jalan. Penentuan tingkat pelayanan jalan didapatkan dari menghitung perbandingan volume kendaraan yang melewati koridor Jalan By Pass Ngurah Rai Jimbaran dan kapasitas jalan By Pass Ngurah Rai Jimbaran. Untuk mendapatkan volume kendaraan, dilakukan pendekatan manual traffic count sementara menghitung kapasitas jalan dilakukan dengan membandingkan kondisi jalan eksisting dengan ketentuan yang ada di Manual Kapasitas Jalan Indonesia

\section{3) Mengidentifikasi Karakteristik Pergerakan}

Karakteristik pergerakan pada penelitian kali ini berkaitan dengan pergerakan yang dilakukan, dilihat dari asal-tujuan pelaku pergerakan. Dari kedua hal tersebut akan teridentifikasi pola pergerakan spasial. Pola pergerakan spasial yang dimaksud adalah pergerakan internal-internal, internal-eksternal, dan eksternal-internal. Alat analisis yang digunakan adalah analisis statistic deskriptif 
4) Mengidentifikasi Karakteristik Bangkitan-Tarikan Untuk Setiap Guna Lahan

Karakteristik bangkitan-tarikan pada penelitian kali ini mencakup deskripsi besaran bangkitan tarikan dari tiap penggunaan lahan perjam selama waktu pengamatan. Besaran bangkitan-tarikan diperoleh dari perhitungan angka trip-rate dari masing-masing tata guna lahan dengan luas tiap tata guna lahan. Angka trip-rate didapat dari survei keluarmasuk kendaraan pada satu atau lebih penggunaan lahan. Angka trip-rate pada penelitian ini dinyatakan dalam satuan pergerakan $/ 100 \mathrm{~m}^{2}$. Alat analisis yang digunakan adalah analisis trip-rate dan analisis statistik deskriptif.

5) Mengidentifikasi Alternatif-Alternatif Strategi TDM

Untuk mendapatkan alternatif strategi yang sesuai dengan kawasan studi, diperlukan perumusan awal strategi-strategi TDM yang berhubungan dengan waktu melalui pengkajian literature dan dibandingkan dengan kondisi eksisting. Strategi-strategi TDM tersebut juga akan ditanyakan kepada pelaku perjalanan apakah strategi-strategi tersebut disetujui untuk diterapkan. Strategi-strategi yang tidak sesuai dengan kondisi eksisting dan preferensi pelaku perjalanan akan direduksi. Alat analisis yang digunakan adalah analisis deskriptif,

6) Mengidentifikasi Besar Pengaruh Pergeseran Waktu Perjalanan terhadap Tingkat Pelayanan Jalan

Pada tahap ini akan dilakukan analisis regresi linear berganda. Terdapat dua variabel yang akan dibuat persamaan regresinya, yaitu variabel dependen yakni derajat kejenuhan (DS) setiap jam selama pengamatan dan variabel independen yakni besar bangkitan-tarikan pergerakan di setiap jam dari setiap penggunaan lahan. Analisis regresi ini bertujuan mengetahui jenis penggunaan lahan apa saja yang besar bangkitan-tarikannya mempengaruhi tingkat pelayanan jalan di Koridor Jalan By Pass Ngurah Rai Jimbaran. Analisis dilakukan dengan bantuan software spss 24 .

\section{HASIL DAN DISKUSI}

\section{A. Gambaran Umum Wilayah Studi}

Koridor Jalan By Pass Jimbaran yang menjadi kawasan penelitian merupakan ruas jalan mulai dari simpang patung Ngurah Rai sampai simpang Universitas Udayana. Berdasarkan RTRW Provinsi Bali, koridor jalan By Pass Ngurah Rai memiliki fungsi kelas jalan Kolektor Primer. Koridor Jalan By Pass Ngurah Rai Jimbaran ini memiliki panjang 4.3 kilometer dengan lebar jalan 14 meter. Koridor Jalan By Pass Ngurah Rai mencakup 3 desa dalam dua kecamatan yang berbeda, yaitu Desa Tuban dan Desa Kedonganan di Kecamatan Kuta dan desa Jimbaran di Kecamatan Kuta Selatan.

Secara umum penggunaan lahan di kawasan penelitian terbagi menjadi kawasan terbangun dan tidak terbangun. Kawasan terbangun terdiri dari penggunaan lahan mayoritas perumahan dan perdagangan dan jasa. Mayoritas penggunaan lahan perdagangan dan jasa terletak di sepanjang koridor pada baris pertama/disisi koridor. Sementara perumahan terletak dibagian dalam kawasan. Jenis penggunaan lain yang terdapat di kawasan penelitian adalah perkantoran dan fasilitas umum seperti sekolah, tempat peribadatan, dan fasilitas umum lainnya.
Tabel 2.

Luas Penggunaan Lahan di Koridor Jalan by Pass Ngurah Rai

\begin{tabular}{cll}
\hline No & Penggunaan Lahan & \multicolumn{1}{c}{ Luas } \\
\hline 1 & Fasilitas Kesehatan & $138.69 \mathrm{~m}^{2}$ \\
2 & Fasilitas Pemerintahan & $1383.27 \mathrm{~m}^{2}$ \\
3 & Fasilitas Pendidikan & $773.96 \mathrm{~m}^{2}$ \\
4 & Fasilitas Peribadatan & $4974.46 \mathrm{~m}^{2}$ \\
5 & Gudang & $7316.27 \mathrm{~m}^{2}$ \\
6 & Kebun Campuran & $24085.09 \mathrm{~m}^{2}$ \\
7 & Lahan Kosong & $38233.48 \mathrm{~m}^{2}$ \\
8 & Mangrove & $90456.63 \mathrm{~m}^{2}$ \\
9 & Perdagangan dan Jasa & $237183.85 \mathrm{~m}^{2}$ \\
10 & Permukiman & $198252.62 \mathrm{~m}^{2}$ \\
11 & Perkantoran Swasta & $2786.4490 \mathrm{~m}^{2}$ \\
\hline \hline
\end{tabular}

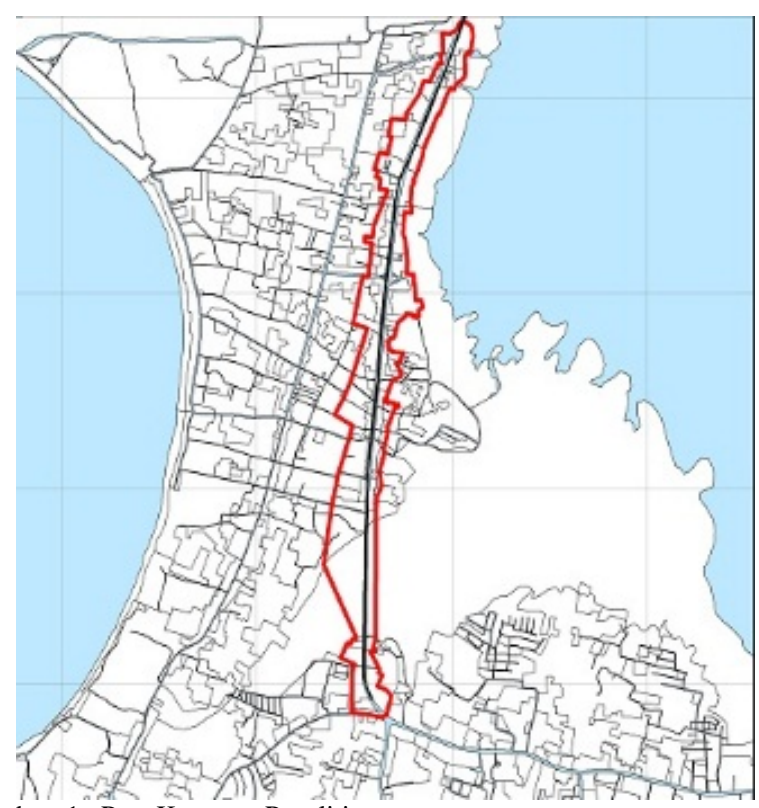

Gambar. 1. Peta Kawasan Penelitian

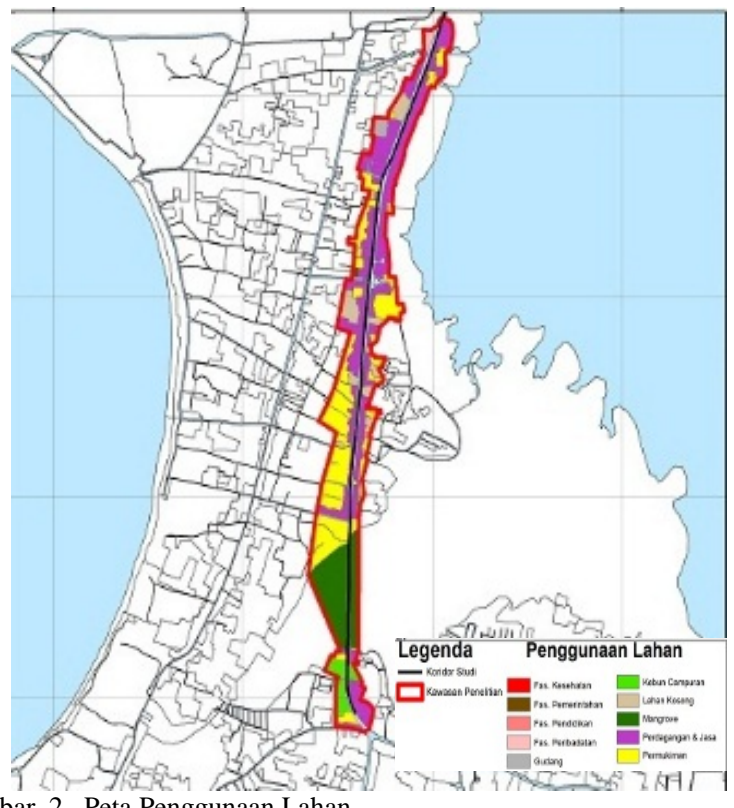

Gambar. 2. Peta Penggunaan Lahan

\section{B. Analisis Karakteristik Pelaku Perjalanan}

Karakteristik pelaku perjalanan di Jalan By Pass Ngurah Rai mencakup lokasi asal-tujuan pelaku perjalanan, waktu tempuh keberangkatan dan waktu tempuh kepulangan, jarak tempuh pelaku perjalanan, maksud perjalanan, serta moda kendaraan yang digunakan pelaku perjalanan. Karakteristik pelaku perjalanan diketahui melalui pengisian kuisioner 
kepada para responden yang kemudian dianalisis dengan analisis statistik deskriptif.

Karakteristik pelaku perjalanan di Koridor Jalan By Pass Ngurah Rai didominasi oleh pelaku perjalanan yang berasal dari luar lokasi penelitian (67.48\%) dan pelaku perjalanan yang bertujuan ke dalam lokasi penelitian (69.33\%). Waktu tempuh pelaku perjalanan yang melalui koridor jalan By Pass Ngurah Rai didominasi (43.56\%) oleh pelaku perjalanan dengan waktu tempuh 15-30 menit dengan dominasi lama aktivitas di lokasi tujuan adalah 8 jam perhari (53\%). Mayoritas pelaku perjalanan (35\%) menempuh jarak lebih dari $10 \mathrm{~km}$ untuk ke lokasi tujuan. Maksud perjalanan didominasi oleh pelaku perjalanan untuk bekerja (74\%) dengan tujuan perjalanan dominan adalah ke jenis penggunaan lahan perdagangan dan jasa (56\%). Terakhir, moda kendaraan yang dominan digunakan oleh pelaku perjalanan adalah sepeda motor.

\section{Analisis Karakteristik Bangkitan-Tarikan di Koridor Jalan By Pass Ngurah Rai}

Karakteristik bangkitan-tarikan di Koridor Jalan By Pass Ngurah Rai Jimbaran dengan pola 16 jam ini mencakup besar bangkitan-tarikan dari setiap jenis penggunaan lahan selama 16 jam, karakteristik pergerakan yang terjadi di koridor Jalan By Pass Ngurah Rai, serta tingkat pelayanan jalan yang terdiri dari arus lalu lintas, kapasitas jalan, dan derajat kejenuhan serta Level of Services (LOS).

Besar bangkitan-tarikan dari masing-masing penggunaan lahan didapatkan melalui survey kendaraan yang keluarmasuk pada bangunan-bangunan dengan jenis penggunaan lahan berbeda-beda. Dari keempat jenis penggunaan lahan tersebut, didapati bahwa jenis penggunaan lahan perdagangan dan jasa yang menjadi pembangkit dan penarik utama pergerakan di koridor jalan By Pass Ngurah Rai.

Tabel 3.

Besar Bangkitan-Tarikan tiap Penggunaan Lahan

\begin{tabular}{lcc}
\hline \hline Penggunaan Lahan & $\begin{array}{c}\text { Total Bangkitan } \\
\text { dan Tarikan (smp) }\end{array}$ & $\begin{array}{c}\text { Total Bangkitan dan } \\
\text { Tarikan (pergerakan) }\end{array}$ \\
\hline Perkantoran & 64.8 & 103 \\
Pemerintahan & & \\
Perkantoran Swasta & 280.0451256 & 364.058663 \\
Fasilitas Pendidikan & 834.8 & 2066 \\
Perdagangan dan Jasa & 44280.6474 & 73682.43 \\
\hline \hline
\end{tabular}

Karakteristik pergerakan yang terjadi di Koridor Jalan $B y$ Pass Ngurah Rai diklasifikasikan menjadi 4, yaitu pergerakan internal-internal sebesar 22\%, pergerakan internal-eksternal sebesar $11 \%$, pergerakan eksternal-internal sebesar $47 \%$ dan pergerakan eksternal-eksternal sebesar 20\%. Jenis pergerakan ini diidentifikasi melalui analisis lokasi asaltujuan pelaku pergerakan. Data lokasi asal dan lokasi tujuan dari pelaku perjalanan diperoleh melalui penyebaran kuisioner. Komposisi karakteristik pergerakan di koridor Jalan By Pass Ngurah Rai adalah sebagai berikut:

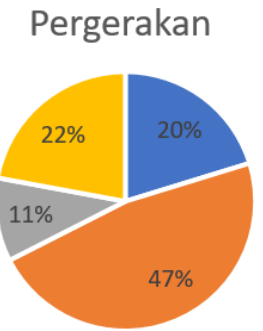

- Eksternal-Eksternal = Eksternal-Internal

= Internal-Eksternal = Internal-Internal

Gambar 3. Persentase komposisi karakteristik pergerakan
Untuk menganalisis tingkat pelayanan jalan ini dibutuhkan data volume arus lalu lintas yang melintasi koridor Jalan By Pass Ngurah Rai Jimbaran dan data Kapasitas Jalan By Pass Ngurah Rai Jimbaran. Berikut tabel dan grafik volume arus kendaraan yang melalui jalan by Pass Ngurah Rai Jimbaran hasil dari traffic counting.

Tabel 4.

Volume Arus Lalu Lintas di Koridor Jalan By Pass Ngurah Rai Jimbaran

\begin{tabular}{cccccc}
\hline \hline Waktu & $\begin{array}{c}\text { MC } \\
\text { (kend) }\end{array}$ & $\begin{array}{c}\text { LV } \\
\text { (kend) }\end{array}$ & $\begin{array}{c}\text { HV } \\
\text { (kend) }\end{array}$ & $\begin{array}{c}\text { UM } \\
\text { (kend) }\end{array}$ & $\begin{array}{c}\text { Total Volume } \\
\text { (SMP/jam) }\end{array}$ \\
\hline $\mathbf{0 6 . 0 0 - 0 7 . 0 0}$ & 4263 & 837 & 172 & 15 & 2765.8 \\
$\mathbf{0 7 . 0 0 - 0 8 . 0 0}$ & 9256 & 1667 & 244 & 21 & 5686.6 \\
$\mathbf{0 8 . 0 0 - 0 9 . 0 0}$ & 8354 & 1485 & 181 & 31 & 5061.9 \\
$\mathbf{0 9 . 0 0 - 1 0 . 0 0}$ & 5349 & 1442 & 133 & 17 & 3754.5 \\
$\mathbf{1 0 . 0 0 - 1 1 . 0 0}$ & 5006 & 1558 & 163 & 7 & 3772.3 \\
$\mathbf{1 1 . 0 0 - 1 2 . 0 0}$ & 4638 & 1584 & 155 & 9 & 3640.7 \\
$\mathbf{1 2 . 0 0 - 1 3 . 0 0}$ & 5317 & 1487 & 175 & 18 & 3841.3 \\
$\mathbf{1 3 . 0 0 - 1 4 . 0 0}$ & 5193 & 1573 & 130 & 28 & 3819.2 \\
$\mathbf{1 4 . 0 0 - 1 5 . 0 0}$ & 5517 & 1494 & 145 & 25 & 3889.3 \\
$\mathbf{1 5 . 0 0 - 1 6 . 0 0}$ & 5761 & 1570 & 128 & 24 & 4040.8 \\
$\mathbf{1 6 . 0 0 - 1 7 . 0 0}$ & 7124 & 1838 & 150 & 15 & 4882.6 \\
$\mathbf{1 7 . 0 0 - 1 8 . 0 0}$ & 7570 & 1609 & 148 & 9 & 4829.4 \\
$\mathbf{1 8 . 0 0 - 1 9 . 0 0}$ & 6442 & 1736 & 125 & 10 & 4475.3 \\
$\mathbf{1 9 . 0 0 - 2 0 . 0 0}$ & 5541 & 1833 & 120 & 4 & 4205.4 \\
$\mathbf{2 0 . 0 0 - 2 1 . 0 0}$ & 4821 & 1765 & 82 & 1 & 3800 \\
$\mathbf{2 1 . 0 0 - 2 2 . 0 0}$ & 4274 & 1370 & 151 & 1 & 3275.9 \\
\hline \hline
\end{tabular}

Volume Arus Lalu Lintas

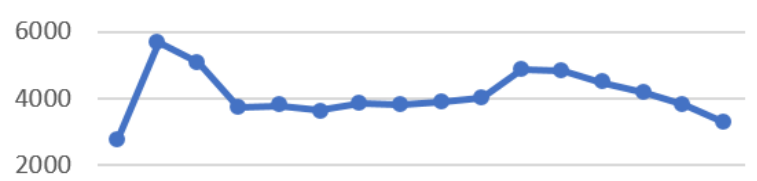

0

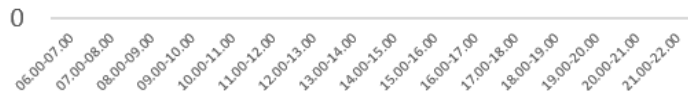

$\longrightarrow$ SMP/Jam

Gambar. 4. Grafik volume Arus LaluLintas.

Untuk menghitung kapasitas Jalan By Pass Ngurah Rai Jimbaran, diperlukan data terkait geometrik jalan By Pass Ngurah Rai Jimbaran meliputi jumlah jalur, jumlah lajur setiap jalur, ketersediaan median jalan, perbedaan lebar tiap jalur, lebar jalan efektif perlajur, lebar bahu jalan, lebar kereb, jarak kereb ke gangguan dan mengamati hambatan samping dari kegiatan yang ada di sepanjang Koridor Jalan By Pass Ngurah Rai Jimbaran serta data ukuran kota yang didapat melalui survey sekunder. Kapasitas Jalan dihitung dengan rumus:

$$
C=C_{0} \times F C_{W} \times F C_{S P} \times F C_{S F} \times F C_{C S}
$$

Tabel 5.

Kapasitas Jalan Koridor Jalan By Pass Ngurah Rai Jimbaran

\begin{tabular}{clc}
\hline \hline No. & \multicolumn{1}{c}{ Parameter } & Nilai \\
\hline 1 & Kapasitas Dasar & 6600 \\
2 & Faktor koreksi akibat lebar jalan & 1.0 \\
3 & Faktor koreksi kapasitas akibat pemisahan arah & 1.0 \\
4 & Faktor penyesuaian hambatan samping & 0.86 \\
5 & Faktor penyesuaian ukuran kota & 0.94 \\
\hline \hline
\end{tabular}

Sehingga kapasitas Koridor Jalan By Pass Ngurah Rai dapat dihitung sebagai berikut:

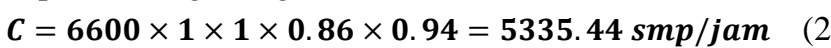

Sementara derajat kejenuhan merupakan rasio volume arus yang melalui satu ruas jalan terhadap kapasitas jalan tersebut dan Level of Service (LOS) adalah penginterpretasian dari derajat kejenuhan itu sendiri. 
Tabel 6.

Derajat Kejenuhan dan LOS di Jalan By Pass Ngurah Rai Jimbaran

\begin{tabular}{crrcc}
\hline \hline Jam & $\begin{array}{c}\text { Volume } \\
\text { (smp/jam) }\end{array}$ & $\begin{array}{c}\text { Kapasitas } \\
\text { (smp/jam) }\end{array}$ & DS & LOS \\
\hline $\mathbf{0 6 . 0 0 - 0 7 . 0 0}$ & 2765.8 & 5335.44 & 0.518383 & $\mathrm{~A}$ \\
$\mathbf{0 7 . 0 0 - 0 8 . 0 0}$ & 5686.6 & 5335.44 & 1.065817 & $\mathrm{~F}$ \\
$\mathbf{0 8 . 0 0 - 0 9 . 0 0}$ & 5061.9 & 5335.44 & 0.948732 & $\mathrm{E}$ \\
$\mathbf{0 9 . 0 0 - 1 0 . 0 0}$ & 3754.5 & 5335.44 & 0.703691 & $\mathrm{C}$ \\
$\mathbf{1 0 . 0 0 - 1 1 . 0 0}$ & 3772.3 & 5335.44 & 0.707027 & $\mathrm{C}$ \\
$\mathbf{1 1 . 0 0 - 1 2 . 0 0}$ & 3640.7 & 5335.44 & 0.682362 & $\mathrm{~B}$ \\
$\mathbf{1 2 . 0 0 - 1 3 . 0 0}$ & 3841.3 & 5335.44 & 0.719959 & $\mathrm{C}$ \\
$\mathbf{1 3 . 0 0 - 1 4 . 0 0}$ & 3819.2 & 5335.44 & 0.715817 & $\mathrm{C}$ \\
$\mathbf{1 4 . 0 0 - 1 5 . 0 0}$ & 3889.3 & 5335.44 & 0.728956 & $\mathrm{C}$ \\
$\mathbf{1 5 . 0 0 - 1 6 . 0 0}$ & 4040.8 & 5335.44 & 0.757351 & $\mathrm{C}$ \\
$\mathbf{1 6 . 0 0 - 1 7 . 0 0}$ & 4882.6 & 5335.44 & 0.915126 & $\mathrm{E}$ \\
$\mathbf{1 7 . 0 0 - 1 8 . 0 0}$ & 4829.4 & 5335.44 & 0.905155 & $\mathrm{E}$ \\
$\mathbf{1 8 . 0 0 - 1 9 . 0 0}$ & 4475.3 & 5335.44 & 0.838787 & $\mathrm{D}$ \\
$\mathbf{1 9 . 0 0 - 2 0 . 0 0}$ & 4205.4 & 5335.44 & 0.788201 & $\mathrm{C}$ \\
$\mathbf{2 0 . 0 0 - 2 1 . 0 0}$ & 3800 & 5335.44 & 0.712219 & $\mathrm{C}$ \\
$\mathbf{2 1 . 0 0 - 2 2 . 0 0}$ & 3275.9 & 5335.44 & 0.613989 & $\mathrm{~B}$ \\
\hline \hline
\end{tabular}

D. Analisis Alternatif Strategi TDM Berdasarkan Preferensi Pelaku Perjalanan

Analisis terhadap strategi TDM berbasis pergeseran waktu ini dilakukan dengan membuat tabulasi dari pernyataan pelaku perjalanan terkait strategi tertentu yang dapat diterapkan di koridor Jalan By Pass Ngurah Rai Jimbaran. Pernyataan yang diberikan terhadap pelaku perjalanan berkaitan dengan strategi TDM berbasis pergeseran waktu yaitu flextime, staggered shift, compressed week, pembatasan waktu berkendara, pembatasan waktu bongkar-muat, dan telecommuting. Berikut Preferensi TDM dari pelaku perjalanan dari setiap jenis tata guna lahan.

Perkantoran Pemerintah

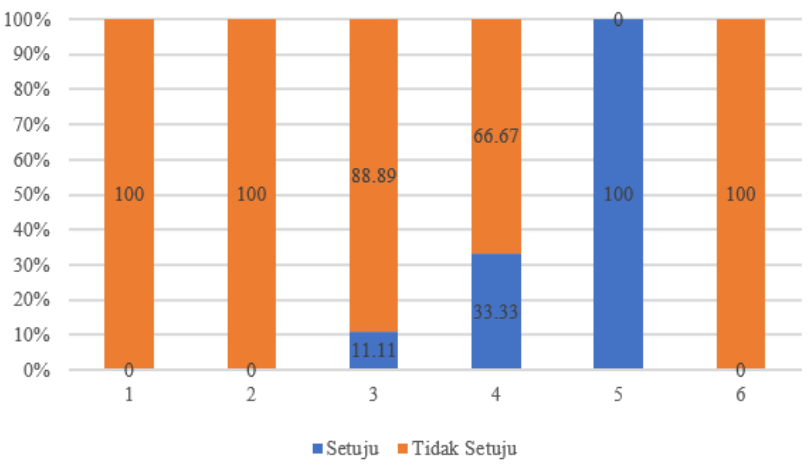

Gambar. 5. Preferensi Strategi TDM di Perkantoran Pemerintah. Perkantoran Swasta

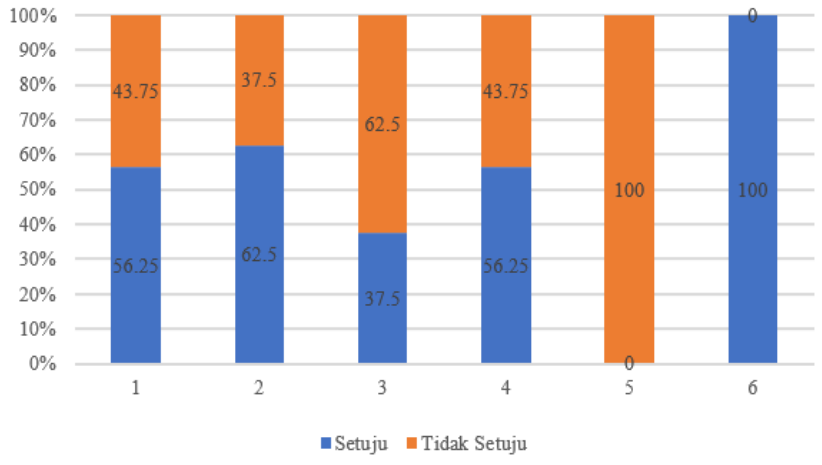

Gambar 6. Preferensi Strategi TDM di Perkantoran Swasta
Fasilitas Pendidikan

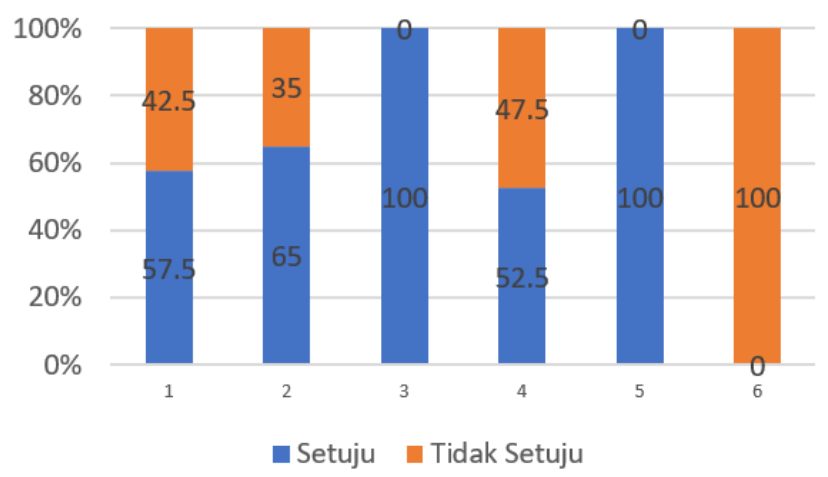

Gambar 7. Preferensi Strategi TDM di Fasilitas Pendidikan Perdagangan dan Jasa

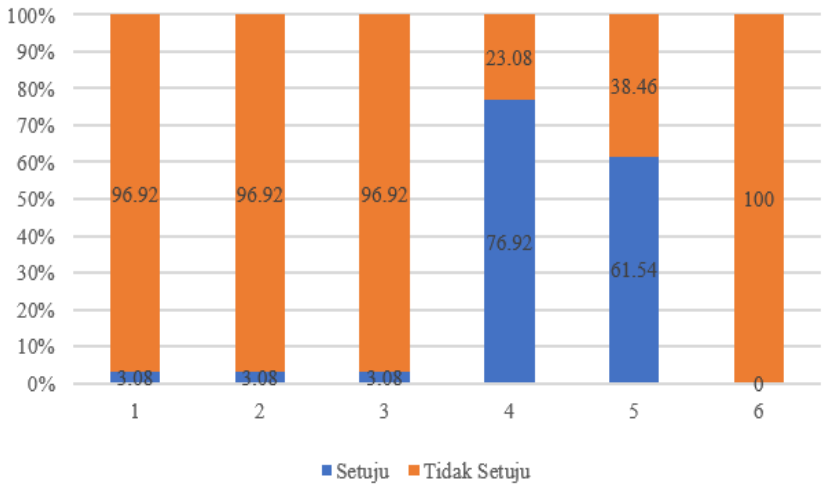

Gambar 8. Preferensi Strategi TDM di Perdagangan dan Jasa

Keterangan

1= Flexible Time

$2=$ Staggered Shift

3= Pembatasan waktu berkendara

4= Compressed week

$5=$ Pembatasan aktivitas bongkar-muat

6= Telecommuting

E. Analisis Pengaruh Pergeseran Waktu Perjalanan terhadap Tingkat Pelayanan Jalan

Akan ada beberapa tahapan analisis untuk mengetahui besar pengaruh pergeseran waktu perjalanan terhadap tingkat pelayanan jalan, yang diidentifikasi melalui derajat kejenuhan. Tahapan awal adalah menganalisa besar pengaruh bangkitan-tarikan dari setiap penggunaan lahan terhadap tingkat pelayanan jalan di Koridor Jalan By Pass Ngurah Rai Bali dengan menggunakan metode perhitungan regresi linier berganda. Berikutnya dilakukan perhitungan estimasi bangkitan-tarikan dari alternatif strategi pergeseran waktu berdasarkan persepsi pelaku perjalanan. Yang terakhir adalah mengeksplorasi besar pergeseran waktu perjalanan dengan mensimulasikan tingkat pelayanan jalan berdasarkan estimasi bangkitan-tarikan hasil penerapan strategi TDM pergeseran waktu sesuai preferensi pelaku perjalanan.

Tabel 7.

Parameter Koefisien Regresi dengan Metode Stepwise

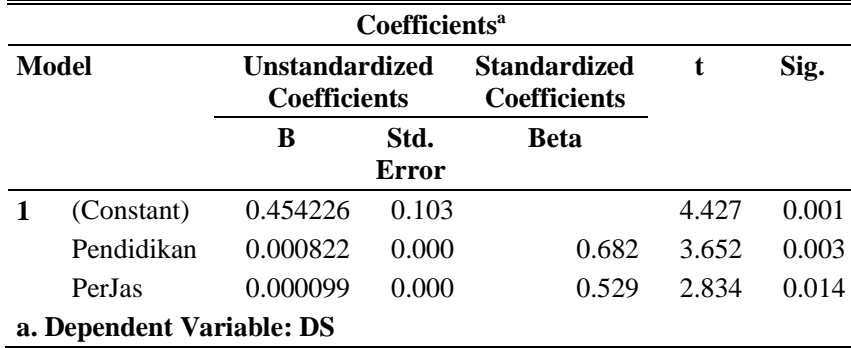


Berdasarkan analisis pengaruh bangkitan-tarikan dengan tingkat pelayanan jalan dengan menggunakan analisis regresi, diketahui bahwa hanya jenis penggunaan lahan fasilitas pendidikan dan perdagangan dan jasa saja yang berpengaruh signifikan terhadap tingkat pelayanan jalan By Pass Ngurah Rai Jimbaran.

Estimasi dilakukan untuk memperkirakan besar bangkitantarikan yang terjadi akibat dari penerapan strategi TDM di Koridor Jalan By Pass Ngurah Rai Jimbaran. Estimasi akan dilakukan berdasarkan hasil analisis strategi TDM yang disetujui oleh pelaku perjalanan. Di samping itu, estimasi besar bangkitan-tarikan hanya diterapkan di penggunaan lahan fasilitas pendidikan serta perdagangan dan jasa karena berdasarkan hasil analisis, hanya kedua penggunaan lahan tersebut yang memiliki pengaruh signifikan terhadap tingkat pelayanan jalan di koridor Jalan By Pass Ngurah Rai Jimbaran.

Perhitungan estimasi besar bangkitan-tarikan dengan strategi flextime akan diterapkan untuk penggunaan lahan fasilitas pendidikan serta perdagangan dan jasa sesuai dengan preferensi pelaku perjalanan yaitu pergeseran pelaku perjalanan sebesar $3.08 \%$ pelaku perjalanan yang bertujuan ke perdagangan dan jasa serta $57.5 \%$ pelaku perjalanan yang bertujuan ke fasilitas pendidikan. Pelaku perjalanan yang mengalami pergeseran waktu perjalanan adalah pelaku perjalanan yang ada pada jam-jam puncak kemacetan.

Perhitungan estimasi besar bangkitan-tarikan dengan strategi staggered shift hanya akan diterapkan untuk penggunaan lahan fasilitas pendidikan karena terdapat pembedaan strata yang jelas yaitu kelas dari para siswa. Dengan memperhitungkan bahwa jumlah perlaku perjalanan sama untuk setiap kelasnya, maka total pergerakan akan dibagi 3 dan didistribusikan pada jam-jam yang berbeda.

Penerapan strategi pembatasan waktu pergerakan hanya diterapkan untuk penggunaan lahan perdagangan dan jasa karena strategi tersebut sudah diterapkan pada penggunaan lahan fasilitas pendidikan (sekolah). Pembatasan waktu pergerakan yang diterapkan di kawasan penelitian yang sesuai dengan preferensi pelaku pergerakan adalah pembatasan pergerakan pada jam padat di siang hari yaitu pada jam 12.00-13.00 dengan besar pergerakan yang dibatasi sesuai preferensi pelaku pergerakan adalah 3.08\% untuk penggunaan lahan perdagangan dan jasa.

Penerapan strategi compressed week akan mengalamai perbedaan jika diterapkan untuk penggunaan lahan fasilitas pendidikan dan perdagangan dan jasa karena terdapat perbedaan lama aktivitas. Berdasarkan survey primer, lama aktivitas pada fasilitas pendidikan adalah 9-10 jam pada saat hari aktif senin-kamis dan hanya 5 jam di hari jumat. Maka hanya terjadi penambahan satu jam di setiap harinya jika skenario Compressed Week ini diterapkan untuk penggunaan lahan fasilitas pendidikan. Sementara untuk pekerja di penggunaan lahan perdagangan dan jasa memiliki lama aktivitas rata-rata 8 jam perhari sehingga dengan melakukan skenario Compressed Week ini akan terjadi penambahan lama aktivitas sebesar 2 jam setiap harinya. Besar pergerakan yang bergeser sesuai preferensi pelaku perjalanan adalah 76.92\% untuk penggunaan lahan perdagangan dan jasa.

Terakhir, penerapan strategi pembatasan aktivitas bongkar muat hanya diterapkan untuk penggunaan lahan perdagangan dan jasa karena aktivitas bongkar muat yang cukup banyak terjadi di penggunaan lahan perdagangan dan jasa saja. Berdasarkan hasil survei, diperoleh jam-jam aktivitas bongkar muat. Dengan asumsi bahwa aktivitas bongkar muat harus dilakukan dengan kuantitas yang sama setiap harinya, maka aktivitas bongkar muat yang terjadi di jam-jam padat akan digeser ke jam tidak padat.

Langkah terakhir adalah dengan melakukan simulasi perubahan volume arus kendaraan akibat penerapan skenarioskenario TDM pergeseran waktu. Pergeseran volume ini nantinya juga akan menentukan derajat kejenuhan setelah skenario diterapkan yang mana derajat kejenuhan ini mengindikasikan tingkat pelayanan jalan. Simulasi perubahan volume dilakukan pada penggunaan lahan yang secara signifikan mempengaruhi tingkat pelayanan jalan yaitu fasilitas pendidikan dan perdagangan dan jasa.

Tabel 8.

Hasil Simulasi Pergeseran Waktu Perjalanan pada Penggunaan Lahan Perdagangan dan Jasa (Kapasitas :5335.44 smp/jam)

\begin{tabular}{|c|c|c|c|c|c|c|}
\hline \multirow{2}{*}{ Jam } & \multicolumn{2}{|c|}{ Pergerakan Total } & \multicolumn{4}{|c|}{ DS Akhir } \\
\hline & Volume & DS Awal & Flexi & Pembatasan waktu & Compressed & Bongkar Muat \\
\hline 06.00-07.00 & 2765.8 & 0.51838 & 0.5517 & 0.51838273 & 0.5183827 & 0.576202386 \\
\hline 07.00-08.00 & 5686.6 & 1.06581 & 1.0512 & 1.06581650 & 1.0658165 & 1.051361591 \\
\hline 08.00-09.00 & 5061.9 & 0.94873 & 0.9299 & 0.94873150 & 0.9487315 & 0.905366766 \\
\hline 09.00-10.00 & 3754.5 & 0.70369 & 0.7036 & 0.70369079 & 0.7036907 & 0.703690792 \\
\hline $10.00-11.00$ & 3772.3 & 0.70702 & 0.7070 & 0.70702697 & 0.7070269 & 0.707026974 \\
\hline 11.00-12.00 & 3640.7 & 0.68236 & 0.6823 & 0.68236171 & 0.6823617 & 0.682361717 \\
\hline $12.00-13.00$ & 3841.3 & 0.71995 & 0.7199 & 0.70009883 & 0.7199593 & 0.683822087 \\
\hline 13.00-14.00 & 3819.2 & 0.71581 & 0.7158 & 0.71581725 & 0.7158172 & 0.751954531 \\
\hline $14.00-15.00$ & 3889.3 & 0.72895 & 0.7622 & 0.72895581 & 0.6331599 & 0.728955812 \\
\hline 15.00-16.00 & 4040.8 & 0.75735 & 0.7427 & 0.75735084 & 0.3929844 & 0.757350846 \\
\hline $16.00-17.00$ & 4882.6 & 0.91512 & 0.8963 & 0.91512602 & 0.5422064 & 0.915126025 \\
\hline $17.00-18.00$ & 4829.4 & 0.90515 & 0.9051 & 0.90515496 & 0.8333080 & 0.854562773 \\
\hline 18.00-19.00 & 4475.3 & 0.83878 & 0.8387 & 0.83878742 & 1.3075029 & 0.88937962 \\
\hline $19.00-20.00$ & 4205.4 & 0.78820 & 0.7882 & 0.78820116 & 1.2244144 & 0.788201161 \\
\hline 20.00-21.00 & 3800 & 0.71221 & 0.7122 & 0.71221867 & 0.7122186 & 0.712218674 \\
\hline 21.00-22.00 & 3275.9 & 0.61398 & 0.6139 & 0.61398872 & 0.6139887 & 0.613988724 \\
\hline \multicolumn{3}{|c|}{ Rata-rata Perubahan } & $6.938 \mathrm{E}-18$ & -0.0012412 & 0 & 3.46945E-17 \\
\hline \multicolumn{3}{|c|}{ Rata-rata Pengurangan Pada Jam Puncak } & -0.010414 & -0.0039721 & -0.08895 & -0.028909 \\
\hline
\end{tabular}


Tabel 9.

Hasil Simulasi Pergeseran Waktu Perjalanan pada Penggunaan Lahan Fasilitas Pendidikan (Kapasitas : 5335.44 smp/jam)

\begin{tabular}{|c|c|c|c|c|c|}
\hline \multirow{2}{*}{ Jam } & \multicolumn{2}{|c|}{ Pergerakan Total } & \multicolumn{3}{|c|}{ DS Akhir } \\
\hline & Volume & DS Awal & Flexible Time & Staggered Shift & Compressed Week \\
\hline 06.00-07.00 & 2765.8 & 0.518382 & 0.55351574 & 0.52955333 & 0.518382739 \\
\hline 07.00-08.00 & 5686.6 & 1.065816 & 1.03068351 & 1.03084282 & 1.065816502 \\
\hline 08.00-09.00 & 5061.9 & 0.948731 & 0.9487315 & 0.9725346 & 0.948731501 \\
\hline $09.00-10.00$ & 3754.5 & 0.703690 & 0.70369079 & 0.70369079 & 0.703690792 \\
\hline $10.00-11.00$ & 3772.3 & 0.707026 & 0.70702697 & 0.70702697 & 0.707026974 \\
\hline 11.00-12.00 & 3640.7 & 0.682361 & 0.68236172 & 0.68236172 & 0.682361717 \\
\hline $12.00-13.00$ & 3841.3 & 0.719959 & 0.71995937 & 0.71995937 & 0.719959366 \\
\hline $13.00-14.00$ & 3819.2 & 0.715817 & 0.71581725 & 0.71581725 & 0.715817252 \\
\hline $14.00-15.00$ & 3889.3 & 0.728955 & 0.72895581 & 0.72895581 & 0.728955812 \\
\hline $15.00-16.00$ & 4040.8 & 0.757350 & 0.79248384 & 0.77050815 & 0.74445594 \\
\hline $16.00-17.00$ & 4882.6 & 0.915126 & 0.87999303 & 0.87704107 & 0.866920067 \\
\hline 17.00-18.00 & 4829.4 & 0.905154 & 0.90515496 & 0.93008262 & 0.966255829 \\
\hline $18.00-19.00$ & 4475.3 & 0.838787 & 0.83878743 & 0.83878743 & 0.838787429 \\
\hline $19.00-20.00$ & 4205.4 & 0.788201 & 0.78820116 & 0.78820116 & 0.788201161 \\
\hline 20.00-21.00 & 3800 & 0.712218 & 0.71221867 & 0.71221867 & 0.712218674 \\
\hline $21.00-22.00$ & 3275.9 & 0.613988 & 0.61398872 & 0.61398872 & 0.613988724 \\
\hline \multicolumn{3}{|c|}{ Rata-rata Perubahan } & $-6.938 \mathrm{E}-18$ & $-1.388 \mathrm{E}-17$ & $-6.93889 \mathrm{E}-18$ \\
\hline \multicolumn{3}{|c|}{ Rata-rata Pengurangan Pada Jam Puncak } & -0.0140532 & -0.004865578 & 0.00257898 \\
\hline
\end{tabular}

Dari hasil perhitungan Tabel 8 dapat dilihat bahwa skenario flexible time dan skenario pembatasan waktu berkendara memiliki rata-rata perubahan DS yang bernilai negatif yang menunjukkan dengan penerapan skenarioskenario tersebut maka angka derajat kejenuhan akan menurun dan tingkat pelayanan jalan membaik. Sementara hal berbeda terjadi jika skenario pembatasan aktivitas bongkar muat diterapkan yaitu terjadi kenaikan rata-rata perubahan DS. Sementara untuk rata-rata pengurangan pada jam puncak, skenario compressed week pada penggunaan lahan perdagangan jasa memiliki nilai yang lebih besar

Tabel 10.

Perubahan LOS setelah Penerapan Skenario TDM di Perdagangan dan Jasa

\begin{tabular}{cccccc}
\hline \hline & LOS & \multicolumn{4}{c}{ LOS Setelah Penerapan Skenario } \\
\cline { 3 - 6 } Jam & Awal & Flexitime & $\begin{array}{c}\text { Pembatasan } \\
\text { Waktu }\end{array}$ & $\begin{array}{c}\text { Compressed } \\
\text { Week }\end{array}$ & $\begin{array}{c}\text { Bongkar } \\
\text { Muat }\end{array}$ \\
\hline $\mathbf{0 6 . 0 0 - 0 7 . 0 0}$ & A & A & A & A & A \\
$\mathbf{0 7 . 0 0 - 0 8 . 0 0}$ & F & F & F & F & F \\
$\mathbf{0 8 . 0 0 - 0 9 . 0 0}$ & E & E & E & E & E \\
$\mathbf{0 9 . 0 0 - 1 0 . 0 0}$ & C & C & C & C & C \\
$\mathbf{1 0 . 0 0 - 1 1 . 0 0}$ & C & C & C & C & C \\
$\mathbf{1 1 . 0 0 - 1 2 . 0 0}$ & B & B & B & B & B \\
$\mathbf{1 2 . 0 0 - 1 3 . 0 0}$ & C & C & C & C & B \\
$\mathbf{1 3 . 0 0 - 1 4 . 0 0}$ & C & C & C & C & C \\
$\mathbf{1 4 . 0 0 - 1 5 . 0 0}$ & C & C & C & B & C \\
$\mathbf{1 5 . 0 0 - 1 6 . 0 0}$ & C & C & C & A & C \\
$\mathbf{1 6 . 0 0 - 1 7 . 0 0}$ & E & D & E & A & E \\
$\mathbf{1 7 . 0 0 - 1 8 . 0 0}$ & E & E & E & D & D \\
$\mathbf{1 8 . 0 0 - 1 9 . 0 0}$ & D & D & D & F & D \\
$\mathbf{1 9 . 0 0 - 2 0 . 0 0}$ & C & C & C & F & C \\
$\mathbf{2 0 . 0 0 - 2 1 . 0 0}$ & C & C & C & C & C \\
$\mathbf{2 1 . 0 0 - 2 2 . 0 0}$ & B & B & B & B & B \\
\hline \hline
\end{tabular}

Dari hasil perhitungan Tabel 10 dapat dilihat bahwa ketiga skenario pergeseran waktu yang dapat diterapkan untuk fasilitas pendidikan rata-rata akan menurunkan derajat kejenuhan setiap jamnya meskipun hanya sedikit. Sementara untuk rata-rata pengurangan pada jam puncak, skenario compressed week pada penggunaan lahan fasilitas pendidikan mengakibatkan peningkatan derajat kejenuhan pada jam-jam puncak.
Tabel 11.

Perubahan LOS setelah Penerapan Skenario TDM di Fasilitas Pendidikan

\begin{tabular}{ccccc}
\hline \hline \multirow{2}{*}{ Jam } & \multirow{2}{*}{$\begin{array}{c}\text { LOS } \\
\text { Awal }\end{array}$} & \multicolumn{2}{c}{ LOS Setelah Penerapan Skenario } \\
\cline { 3 - 5 } & & Flexitime & $\begin{array}{c}\text { Staggered } \\
\text { Shift }\end{array}$ & $\begin{array}{c}\text { Compressed } \\
\text { Week }\end{array}$ \\
\hline $\mathbf{0 6 . 0 0 - 0 7 . 0 0}$ & A & A & A & A \\
$\mathbf{0 7 . 0 0 - 0 8 . 0 0}$ & F & F & F & F \\
$\mathbf{0 8 . 0 0 - 0 9 . 0 0}$ & E & E & E & E \\
$\mathbf{0 9 . 0 0 - 1 0 . 0 0}$ & C & C & C & C \\
$\mathbf{1 0 . 0 0 - 1 1 . 0 0}$ & C & C & C & C \\
$\mathbf{1 1 . 0 0 - 1 2 . 0 0}$ & B & B & B & B \\
$\mathbf{1 2 . 0 0 - 1 3 . 0 0}$ & C & C & C & C \\
$\mathbf{1 3 . 0 0 - 1 4 . 0 0}$ & C & C & C & C \\
$\mathbf{1 4 . 0 0 - 1 5 . 0 0}$ & C & C & C & C \\
$\mathbf{1 5 . 0 0 - 1 6 . 0 0}$ & C & C & C & C \\
$\mathbf{1 6 . 0 0 - 1 7 . 0 0}$ & E & D & D & D \\
$\mathbf{1 7 . 0 0 - 1 8 . 0 0}$ & E & E & E & E \\
$\mathbf{1 8 . 0 0 - 1 9 . 0 0}$ & D & D & D & D \\
$\mathbf{1 9 . 0 0 - 2 0 . 0 0}$ & C & C & C & C \\
$\mathbf{2 0 . 0 0 - 2 1 . 0 0}$ & C & C & C & C \\
$\mathbf{2 1 . 0 0 - 2 2 . 0 0}$ & B & B & B & B \\
\hline \hline
\end{tabular}

\section{KESIMPULAN}

Berdasarkan hasil simulasi tingkat pelayanan jalan dengan penerapan strategi TDM pergeseran waktu, skenario flexibletime hanya memberikan sedikit perubahan terhadap tingkat pelayanan jalan, sementara skenario compressed week memberikan perubahan yang sangat signifikan terhadap tingkat pelayanan jalan pada jam-jam tertentu, serta skenario TDM pergeseran waktu yang lainnya hanya memberikan sedikit perubahan pada jam tertentu. Terjadi perubahan yang cukup signifikan pada jam-jam puncak ketika skenario diterapkan di penggunaan lahan perdagangan dan jasa namun hanya terjadi perubahan signifikan terhadap LOS jika skenario TDM pergeseran waktu diterapkan di penggunaan lahan fasilitas pendidikan pada jam 16.00-17.00. 


\section{DAFTAR PUSTAKA}

[1] Dinas PU Bina Marga, "Manual Kapasitas Jalan Indonesia," Jakarta, 1997.

[2] A. Alhadar, “Analisis kinerja jalan dalam upaya mengatasi kemacetan lalul lintas pada ruas simpang bersinyal di Kota Palu," SMARTek, vol. 9, no. 4, pp. 327-336, Sep. 2012.

[3] A. Broaddus, T. Litman, and G. Menon, "Transportation demand management,” Eschborn, Germany, 2009.

[4] O. Z. Tamin, "Konsep manajemen kebutuhab transportasi (MKT) sebagai alternatif pemecah masalah transportasi perkotaan di DKI Jakarta,” J. Reg. City Plan., vol. 10, no. 1, pp. 10-22, 1990

[5] E. Ferguson, Travel demand management and public policy. Aldershot: Ashgate, 2000. 